the second or third day after the injection she developed symptoms of purpura. Even where she was given hypodermatic injections, there was an extravasation of blood under the skin. She suffered considerable hemorrhage from the mouth and bowels after the second or third day.

Dr. F. R. HAGNER, Washington: I saw in consultation a case in which a 25 per cent. argyrol solution had been used. This was done by Dr. G. Brown Miller of Washington, an able gynecologist. He assured me that he put in less than 8 c.c. of argyrol. This woman was about 70 years of age and was supposed to have a tumor of the kidney. Immediately after the injection she complained of discomfort and pain in the precordial region. For twenty-four hours she had practically complete suppression of urine. In the next twenty-four hours she excreted approximately 16 ounces. About the third day she began to pass blood by the bowcl, her stomach became very much distended, a stomach-tube was passed and her stomach was found filled with blood. She had hemorrhages from the gums, nose, and blood in the urine and petechial hemorrhages over the entire body. When I saw her I suspected she might have mercuric chlorid poisoning. It looked like a case of metallic poisoning. Has any one seen any symptoms of metallic poisoning in any of these cases in which the colloidal silver salts have been used? We were unable to get a necropsy in this case.

Dr. H. D. FurNiss, New York: I had a patient who gave much the same history as the patient reported by Dr. Hagner. She was injected with collargol, and within a few minutes she had an immense amount of pain. Following that the condition cleared up, but on the third day I explored the left kidney and found an anomalous blood-vessel running to the lower pole. Three days after the operation and five days after the injection the patient had suppression of urine, which lasted for eight days, and during that time there was no more than 1 ounce excreted in any one day. At the end of that time I decapsulated the right kidney. I was afraid of getting too much hemorrhage from the side $I$ had previously operated on. Within twenty-four hours after the decapsulation urine began to be excreted, and was excreted in fairly good amount for the next four days, at the end of which time she died; but after the operation this patient had hemorrhages from the nose and mouth, just as Dr. Hagner has reported. Collargol is sometimes used therapeutically intravenously, in a percentage which is a solution. In these cases in which it is injected into the kidney it is in the form of an emulsion, and it has struck me that that probably accounts for the emboli that are found.

Dr. Martin Krotoszynir, San Francisco: I made an observation similar to that of Dr. Hagner in a woman of about 40 , who after injection of a small amount of a 20 per cent. cargentos solution developed symptoms similar to those described by Roessle, and which this anthor considered to be due to an acute silver toxemia or argyria. I cannot share Dr. Eisendrath's optimism regarding the avoidance of all dangers connected with pyelography by regulating the pressure in injecting the silver salt. Shortly before leaving home I injected in a man of 45 , with a unilateral pyuria of doubtful character, under very low pressure, 2 or 3 c.c. of a 10 per cent. collargol solution. In spite of the utmost precaution in the procedure and in spite of discontinuing the injection at the first sign of discomfort on the part of the patient, the exposed kidney presented a focus on its capsule which was proved by the pathologist to be due to penetration of collargol through the renal tubules. This observation and similar ones recorded in the literature by others prove that the last word on the cause of pyelographic mishaps is not yet spoken. It is to be hoped, though, that the dangers of pyelography will be avoidable so that this important diagnostic method, which we would not like to dispense with in our armamentarium, will not become entirely discredited.

Dr. Frederick R. Charlton, Indianapolis: I report a death from collargol. This patient had a tumor mass (necropsy was not obtained) perhaps the size of a small grapefruit, supposedly hydronephrotic. This was a year ago, before the danger of using a piston syringe was so fully understood. We injected 15 c.c. of a 25 per cent. collargol solution.
Before the injection was completed the patient was complaining of distress. I waited for a moment until he was easier, and then continued the injection until I had injected the full 15 c.c. I labored under the impression at that time that perhaps it would be somewhat difficult to get a dangerous pressure from that amount of fluid, feeling that a certain percentage of it would find its way hackward down the course of the ureter along the catheter. That belief does not seem to be borne out by tater experiences. We took our roentgenogram, getting an excellent one, showing extravasations of collargol well out toward the cortex and outlining a large mass of some kind. Our patient went into collapse and died in eight hours. This man had walked into the Roentgen-ray laboratory, so that the case was a distressing one, and we could not get a necropsy for obvious reasons. I felt at the time that perhaps it was due more to cardiac collapse than anything else. Granting that I had produced some small rupture in the pelvis, I could not see why that should cause immediate death. I did not feel at the time that collargol was to be regarded as dangerous from the point of view of its drug properties. And so in trying to explain my patient's death I felt that perhaps we had a bad myocardium, that I had produced just enough pain to cause consideralle shock, and that his heart had not been able to rally afier such shock.

\section{FRACTURES OF THE INFERIOR MAXILLA}

A REPORT OF 1,065 CASES TREATED*

\section{HENRY S. DUNNING, M.D., D.D.S. NEW YORK}

During the last eight years I have had quite an opportunity of studying fractures of the maxillary bones at the New York College of Dentistry. At the college we have a large daily oral surgery clinic under the direction of Prof. Faneuil D. Weisse and myself, which is fed by the outpatient department of nearly all of the large hospitals of Manhattan. Since the founding of the oral surgery clinic at the college in 1906, we have treated over 1,200 fractures of the inferior maxillary bone, but I am sorry to say that at this time I can present figures taken from only 1,065 cases, as some of the records are not very complete.

Stimson says, "By fracture, in the surgical sense, is meant the breaking of a bone or cartilage." The liability of a bone to fracture depends on its shape, size and degree of exposure to external violence or trauma, and also to its exposure to extreme muscular action. On account of its peculiar horseshoe shape, its prominence and its unsupported position, and the fact that it is somewhat weakened by the carrying of teeth that often become diseased, the inferior maxillary bone is the most frequently fractured bone of the face.

Stimson shows that in 14,566 fractures of all the bones of the body treated at the Hudson Street Hospital (1894-1905), 502 of these were fractures of the inferior maxilla. From his figures this bone is the tenth on the list as being most of ten fractured. Another reason for its frequency to fracture is its weakened condition because of physiologic absorption after teeth are extracted. Most fractures of the body of the bone proper, or of the rami, are complete fractures, and it is the complete fractures that will be discussed to-day.

* Read before the Sectio on Stomatology at the Sixty-Fifth Annual Session of the American Medical Association, Atlantic City, N. J., June, 1914.

* Because of lack of space this article is abbreviated in THE Journal. The complete article appears in the Transactions of the Section and in the author's reprints. 
TABLE 1.-INJURY AND CAUSES IN 1,065 CASES OF FRAC. TURE OF THE INFERIOR MAXILLA*

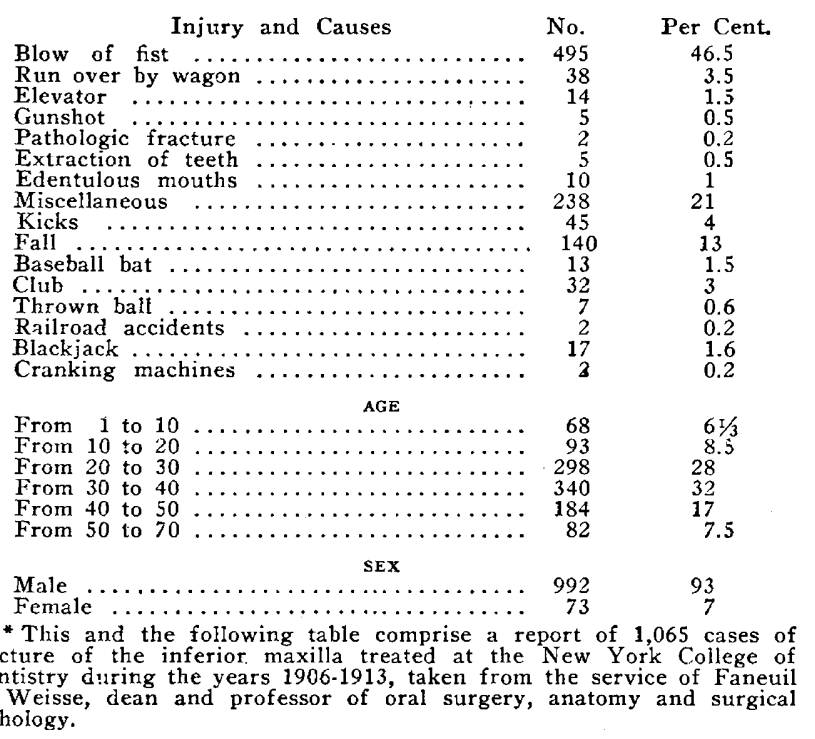

The fracture of the alveolar process is very numerous and occurs often on the extraction of a tooth. Complete fractures of the body of the bone are generally vertical in direction, and about 98 per cent. of these fractures are compounded to the mouth, when there are teeth present. This is due to the fact that most of the fractures of the body of the bone occur at the alveolus of a tooth, and runs along the tooth cavity to its end, and then enters the body of the bone in the same direction. The fracture of this bone is the most often compound fracture of any in the body, owing to its thin covering of gum tissue and mucous membrane, and of course, for

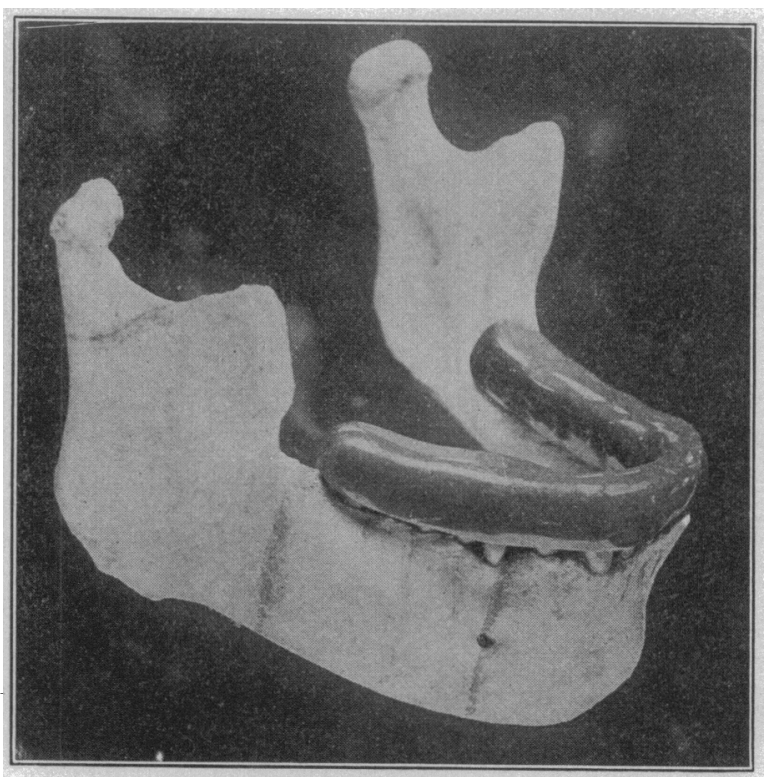

Fig. 1.-Cap splint or single arch splint used whenever ther are one or more sound teeth on either side of the line of fracture
Varieties of Fractures.-1. Complete. 2. Incomplete. 3. Single. 4. Multiple. 5. Simple. 6. Compound. 7. Comminuted or splintered. Any of the foregoing fractures may be complicated when nerves, blood vessels and other structures are involved. tive.

Symptoms of Fractures.-1. Objective. 2. Subjec-

Objective Symptoms.-1. Deformity. Fractured portions of bone in faulty position, malocclusion of teeth ; swelling and edema of soft parts, enlargement of glands.

2. Abnormal mobility of the fractured parts of bone or false point of motion.

3. Crepitus. The grating of the fractured end of one bone on another, obtained in complete fractures by holding one fragment of bone firmly between the fingers and moving the other on it.

4. Increased salivation, or drooling, very marked as a rule, and patient is forced to expectorate continually, owing to reflex excitations of vasomotor nerve.

5. Hemorrhage and ecchymosis, often present when the soft parts have been traumatized. The gums surrounding the point of fracture are often discolored and congested, owing to rupture of small capillaries, and extravasation of blood into the tissues.

6. Inability to close teeth together with much force on account of the lack of muscular control.

7. Teeth often loosened at point of fracture, and the teeth often fractured or chipped.

8. Infection and abscesses and necrosis at line of fracture.

Subjective Symptoms.-1. Pain in moving jaw when eating, swallowing, etc.

2. Pain and "soreness" of throat, die to absorption of toxic material by adenoid tissue of throat.

3. Inability to masticate this reason, it is the most often infected fracture It is not often compounded to the face. The vertical direction is also due to the fact that the bone is most often fractured by a blow that bends the bone at right angles to its long axis. A blow on one side of the jaw will sometimes cause a fracture on the opposite side in the same way that a blow on a barrel hoop will be felt at a point opposite the point where the blow is received. This is called "fracture by coutre coup."

In edentulous mouths the fractures are usually simple ones, and are not so apt to be vertical as there is no tooth cavity to weaken the bone, and to direct the line of fracture. These of ten become compound fractures, as the gum is so thin that pressure of an interdental splint often causes a sharp edge of bone to penetrate the soft tissue.

Fractures of the alveolar process are usually in the anterior part of the jaw, where they are more exposed to trauma.

\begin{tabular}{|c|c|c|}
\hline Number of Fractures: & No. & Per Cent. \\
\hline 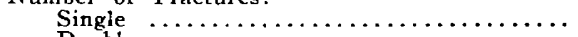 & 951 & 89 \\
\hline Double $\ldots \ldots \ldots \ldots \ldots \ldots \ldots \ldots \ldots$ & 108 & 10 \\
\hline Triple $\quad \ldots \ldots \ldots \ldots \ldots \ldots \ldots \ldots \ldots \ldots$ & 5 & 0.5 \\
\hline Quadruple $\ldots \ldots \ldots \ldots \ldots \ldots \ldots \ldots \ldots \ldots \ldots$ & 1 & 0.1 \\
\hline Kinds of Fracture: & & \\
\hline 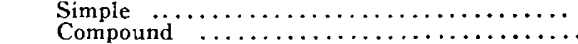 & 70 & 6.5 \\
\hline $\begin{array}{l}\text { Compound } \ldots \ldots \ldots \ldots \ldots \ldots \ldots \ldots \ldots \ldots \\
\text { Location of Fracture: }\end{array}$ & 995 & 93.5 \\
\hline $\begin{array}{l}\text { Location of Fracture: } \\
\text { Median line } \ldots \ldots \ldots \ldots \ldots \ldots \ldots \ldots \ldots\end{array}$ & & \\
\hline Median line $\ldots \ldots \ldots \ldots \ldots \ldots \ldots \ldots \ldots$ & 69 & 6.5 \\
\hline $\begin{array}{l}\text { Right Side: } \\
\text { Lateral regiont }\end{array}$ & & \\
\hline Lateral region $\ldots \ldots \ldots$ & 112 & 10.5 \\
\hline Cuspid region $\ldots \ldots \ldots \ldots$ & 96 & 9 \\
\hline Bicuspid region ......... & 122 & 10.75 \\
\hline First malar region $\ldots \ldots \ldots \ldots \ldots \ldots \ldots$ & 86 & \\
\hline Second molar region $\ldots \ldots \ldots \ldots \ldots \ldots$ & 123 & 10.75 \\
\hline Third molar region $\ldots \ldots \ldots \ldots \ldots \ldots \ldots$ & 66 & \\
\hline Ramus $\ldots \ldots \ldots \ldots \ldots$ & 26 & 2.5 \\
\hline Condyle $\ldots \ldots \ldots \ldots$ & 3 & 0.6 \\
\hline Coronoid process $\ldots \ldots \ldots \ldots \ldots \ldots \ldots \ldots$ & 2 & 0.2 \\
\hline Left Side: & & \\
\hline Lateral rezion & 65 & 6 \\
\hline Cuspid region. & 87 & 8 \\
\hline Bicuspid region ... & 108 & 10.5 \\
\hline First molar region... & $\begin{array}{r}94 \\
144\end{array}$ & 13.5 \\
\hline $\begin{array}{l}\text { Second molar region } \ldots \ldots \ldots \ldots \ldots \ldots \ldots \ldots \ldots \\
\text { Third molar region. } \ldots \ldots \ldots \ldots \ldots \ldots \ldots \ldots\end{array}$ & $\begin{array}{r}144 \\
70\end{array}$ & 6.5 \\
\hline Ramus $\ldots \ldots \ldots \ldots \ldots \ldots \ldots \ldots \ldots \ldots$ & 27 & 2.5 \\
\hline$\ldots \ldots \ldots \ldots \ldots$ & 2 & 0.2 \\
\hline ocess & 0 & 0 \\
\hline
\end{tabular}


4. Pain on pressure at point of fracture.

5. Difficulty in talking and swallowing.

6. Partial and complete anesthesia around point of fracture, due to injury of branches of the third division of the fifth nerve and followed sometimes by slight anesthesia of the tongue.

Causes of Fractures.-1. Predisposing causes. 2. Direct causes.

Under predisposing causes we have:

A. Age. Both extremes of age-the very young child and in the old person. Young children's jaws do not fracture as easily as do those of old people, because the bone is more cartilaginous and springy, owing to the fact that the bones are not completely calcified. Around the ages of 6 to 10 years they are of ten greatly weakened by the eruption of the second teeth. Spaces are present in the body of the bone to hold these large erupting teeth, and quite often one finds the line of fracture through these cavities. In old persons, of course, all bones are more brittle, more poorly nourished, and the maxilla is often greatly thinned by the absorption that has taken place after the teeth have been lost. The most common age for fracture is between the ages of 30 and 40 years. Men during these ages are more often exposed to trauma, as their activities are greater.

B. Disease is another predisposing cause of fracture. Under this heading we have spontaneous or pathologic fracture :

(a) Necrosis of bone caused by infection, osteomyelitis, arsenic poisoning and phosphorus poisoning.

(b) Syphilis of bone.

(c) Tuberculosis of bone.

(d) Cysts of various

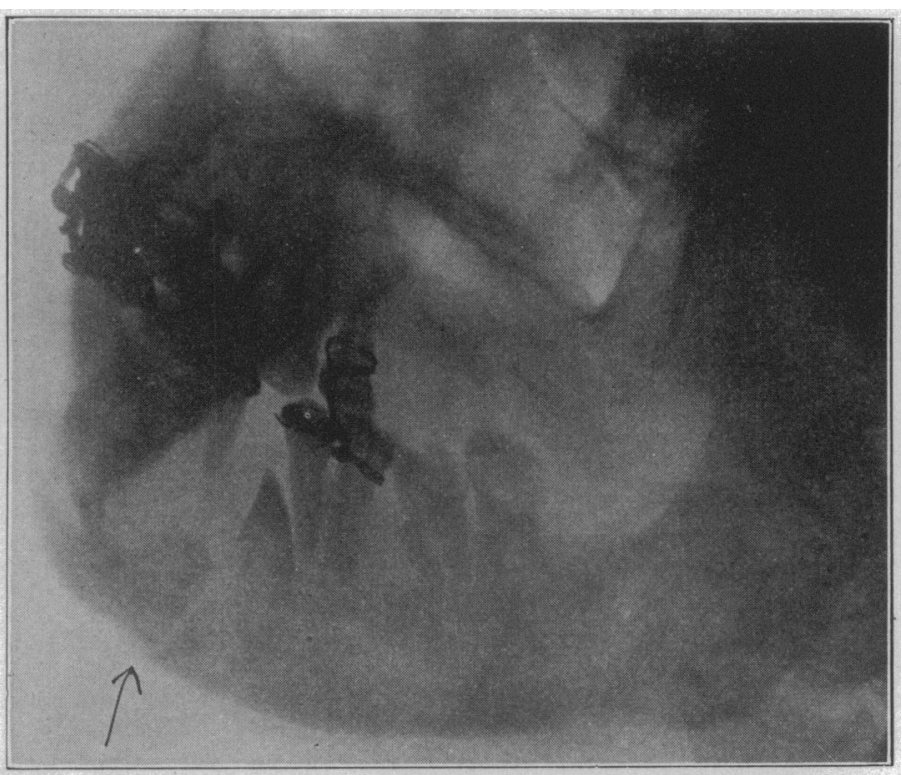

Fig. 2.-Impacted cuspid in line of fracture; a predisposing cause and an obstacle to healthy repair of bone.
Location of Fractures.-I do not agree with Stimson when he says that the most common seat of fracture of the lower jaw is at or near the median line (see tables).

Fractures at the median line show, as a rule, very little deformity as the parts are pulled on more evenly by the muscles on either side of the line of fracture. These fractures are not so common as in other regions of the jaw on account of the increased thickness at the symphysis.

The deformity at the canine region is not so marked as a rule, as the nearer to the median line the more even is the play of muscles, and the less deformity on this account.

The fracture at the bicuspid region of ten shows quite a marked deformity, the anterior fragment being drawn downward and backward, and the posterior fragment upward and outward.

Fractures between the first and second molar teeth may cause a good deal of deformity; generally the bone anterior to the fracture is depressed by the pull downward of the hyoid group of muscles. The posterior fragment is, as a rule, thrown upward by the contraction of the masseter and pterygoid muscles. The anterior fragment is also apt to be drawn backward, partly by the action of the hyoid muscles.

Fractures of the ramus itself do not show very much deformity, as the masseter and pterygoid muscles hold the fractured parts together as a rule. In these fractures the median line of the lower jaw does not coincide with the upper, as the whole lower jaw may be drawn over toward the fractured side if there is any overriding of the fractured kinds, including dentigerous cysts, in which large cavities are formed in the bone.

(e) Osteomalacia.

(f) Rickets.

(g) Tumors, odontoma, sarcoma, osteosarcoma, etc.

C. Occupation is a predisposing cause. Drivers, longshoremen, chauffeurs, waiters, pugilists, etc.

D. Sex: about ten times as common in man as in woman.

Under direct causes:

A. Blows of fist most frequent.

B. Blows of clubs, etc., next .

C. Automobile accidents.

D. Elevator accidents.

E. Railroad accidents.

F. Gunshot cases.

G. In extracting teeth. A complete fracture of the inferior maxilla is caused very rarely by the extraction of teeth, and I can only count one or two cases in which the jaw has been actually fractured by careless extraction. 
coronoid process is fractured by the sudden contraction of the temporal muscle, but this has not been proved conclusively.

Fractures posterior to the third molar at the junction of the ramus and the body of the bone are quite numerous, and the fractures in these cases are often in an oblique direction. Displacements in these cases are

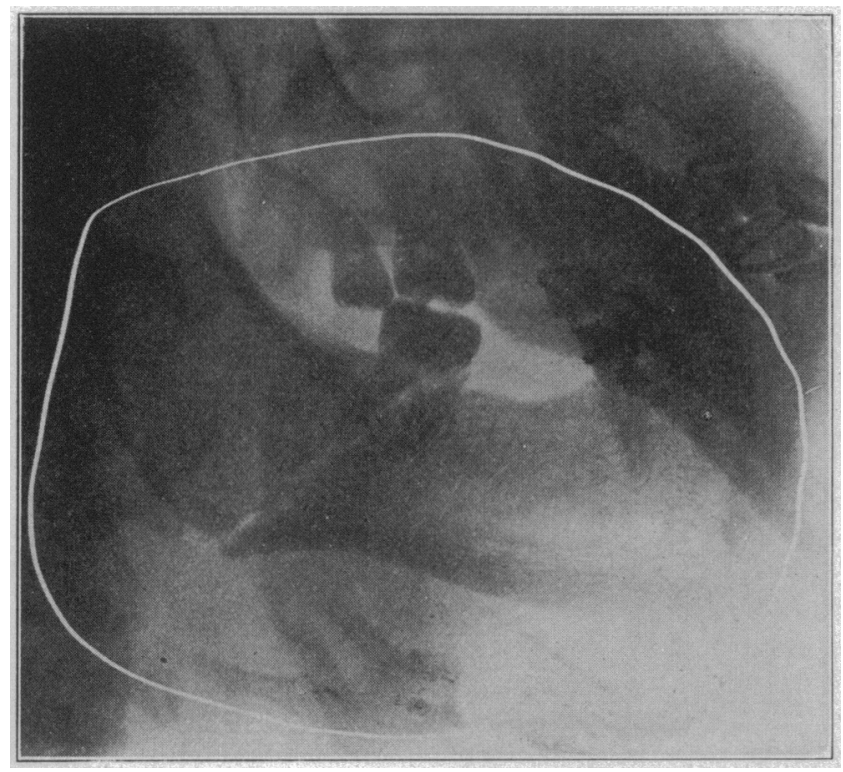

Fig. 3.-Fracture of tooth and jaw; tooth becomes infected and mus te removed.

not very marked, as the parts are held together by the masseter and internal pterygoid muscles.

Single and Multiple Fractures.-Single fractures of the jaws are, of course, more common, but double fractures are frequently seen as shown by my tables. Triple fractures are quite rare and I have seen only four or five in the foregoing series. Quadruple fractures are extremely rare, and I have seen only one case. Teeth are often loosened and fractured in complete fractures of the bone. Multiple fractures are generally more painful, owing to the fact that there is usually more trauma, and the fractured ends of bone impinge in more than one place on the inferior dental nerve. In these cases, when trauma has been great there is often an area of anesthesia around or near the line of fracture. This condition of ten remains long after the jaw has united.

The location and number of fractures of the lower jaw depend a great deal on the articulation of the jaws, and to the arrangement of the occluding teeth. Also to the manner in which the trauma is produced. Slight dislocation of the bone often occurs when the bone has been fractured in more than one place, especially when the fractures a e bilateral, as the shape of the bone is not supported and its arch collapses. By the play of the powerful hyoid muscles, the bone is then drawn downward and the condyles are often displaced slightly from the glenoid cavities.

\section{TREATMENT}

In treating fractures of the jaws the general hygienic condition of the mouth must be carefully considered and the general physical condition of the patient noted. The teeth should be cleansed first of all-not too minutely removing all calcareous deposits, but the soft food particles and infectious material should be removed from the teeth and soft parts. The gums and teeth should be cleaned every two hours by means of cotton swabs on a stick soaked in hydrogendioxid and water (equal parts). A roentgenogram should now be taken. The next step should be the extraction of any broken-down decayed roots, and any loose teeth near the point of fracture. If these are not removed they often cause abscesses which are generally very troublesome. After the mouth is rendered as clean as possible, lacerations of gums and soft parts have been treated, and roots have been removed, the next important step is to consider the means of proper coaptation and fixation of the bony parts.

If there is very much edeme and swelling of the soft tissues, it is sometimes well to apply hot or cold compresses, and wait until the swelling subsides, meanwhile keeping the mouth clean, and the jaws held together with a Barton bandage.

In taking up the matter of fixation of the bony parts, we must consider the mechanics of the case. We must think of what forces are going to act on the different parts of the bone, and how much strength it will require to hold the fractured parts together for a given time.

It is comparatively easy to immobilize a fractured leg or arm, but a different story to keep the inferior maxilla from moving. The inferior maxillary bone is moving continually. The powerful muscles of the jaws are pulling and contracting in different directions all the time. The fractured parts move every time the patient eats, swallows, coughs, talks, sneezes, etc., unless held by a well-constructed mechanical appliance. We must remember that the average splint will remain in the mouth about thirty days under more or less constant strain. These appliances should be strong, com-

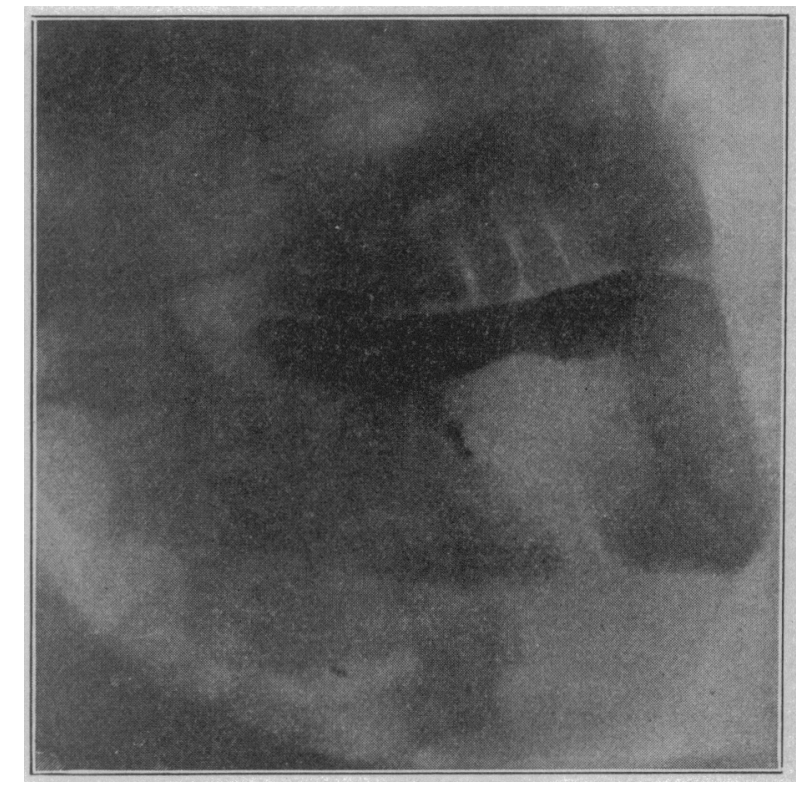

Fig. 4.-Gunshot fracture; cap splint in pesition.

fortable and as small as possible, and should be arranged so that the patient can chew with splint in position if possible. (Of course the articulation of the teeth should be carefully studied and the functions of jaw and teeth accurately restored as a final result.

In discussing the actual method of splinting fractured jaws it will be well to consider again the location of iractures. 
In fractures of the median line, when there is not much deformity, and when there are one or more sound teeth on either side of fracture, the best method to adopt is the use of a cap splint or single arch splint made of rubber or metal. Wires or interdental splints should never be used in these cases; as they are clumsy and dirty, and the patient is unable to chew with them.

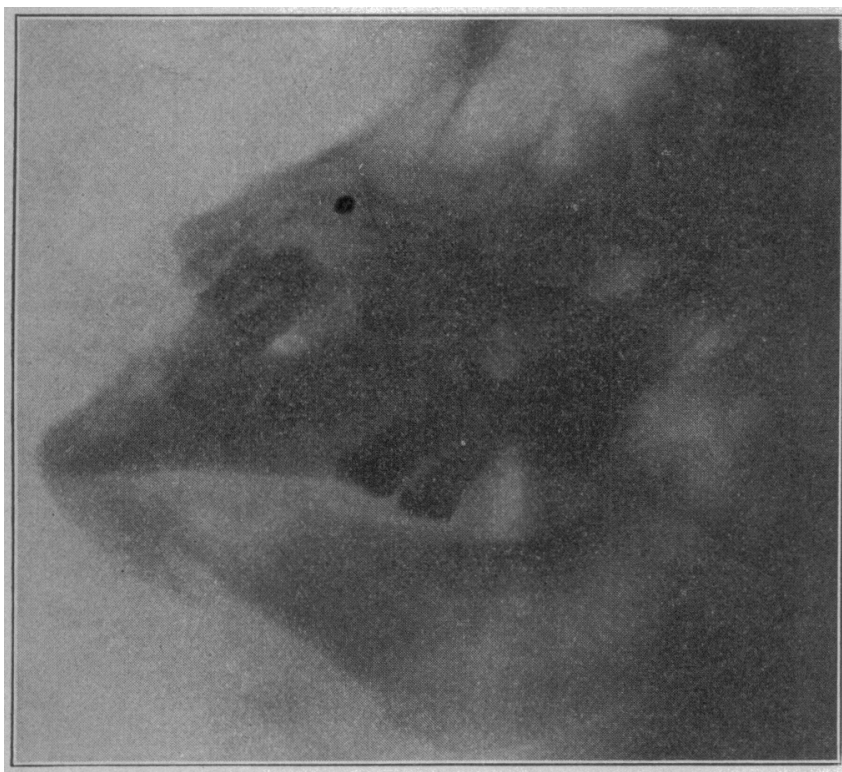

Fig. 5.-Pathologic fracture; no history of any trauma, but long his tory of chronic abscesses of jaw. Fracture occurred while patient was eating crust of bread.

In fractures at the molar region, when there are one or more good teeth, the cap splint can be used, but if the teeth are not strong, wiring the entire lower jaw to the upper is a good procedure for about ten days, until there is partial union, and then the cap splint may be put on. When there is much deformity in this case, wiring the upper and lower jaw together, after applying Angle's bands, is a good plan. Mouths become very foul, and septic poisoning of the entire system may follow and also infection of the respiratory organs when the jaws are wired together for a long period. Carl Beck reports a case of inspiration pneumonia which ended fatally because of the filthy condition of a mouth resulting from the fracture of the inferior maxilla.

Fractures back of the third molar, and in the ramus are best treated by interdental splints, and wiring jaws with Angle's wires. The wiring method is the best if there is much deformity, as sometimes it is difficult to force a jaw into an interdental splint and hold it there with a bandage, especially if the deformity is marlied.

I disagree with Frederick J. Cotton when he advises the open operation and surgical wiring of fractures in this region. It is in most cases unnecessary. It is of course impossible to hold the ramus by any splint in the mouth, but the anterior fractured end of bone can be held to the ramus by wiring the upper and lower jaws together. In children all fractures are best treated by small modified interdental splints. The teeth are not strong enough to wire and it is difficult and unsatisfactory to cement a cap splint on the teeth.

Surgically wiring through the body of the bone for fractures in any location should not be done. Very poor results are obtained by this method, as most cases terminate in infection and necrosis. We have not had to resort to this treatment in over 1,200 cases.

A method lately used has been the screwing of a Lane plate to the under border of the jaw and good results have been obtained, but this method is unnecessary. Outside splints or apparatus on the face are seldom needed and have not been used at all by us in over 1,000 cases treated at the college.

\section{COMPLICATIONS}

Infection is the chief source of annoyance and danger in fracture cases. A large percentage of all compound fractures are infected, and in many of these cases there is necrosis later. Abscesses often form at the point of fracture, and later sinuses form which are apt to break on the face owing to the fact that the pus gravitates downward. Comminuted or splintered fractures are nearly always followed by abscesses and necrosis. Union in these infected cases is generally delayed, and suppurating sinuses may continue for months. A good deal of necrotic bone in these cases is eventually thrown off.

Deep abscesses of the neck are often dangerous, and may extend along the deep fascia into the anterior mediastinum. Edema of the glottis may follow and fatal results occur. Ludwig's angina sometimes results.

Faulty union is quite often encountered, often in children when the bones sometimes unite before one can get on a suitable appliance.

Partial and complete ankylosis often occurs in fracture of the condyles, resulting in loss of function and malocclusion.

Non-union or pseudarthrosis occurs infrequently, generally owing to loss of bone following comminution

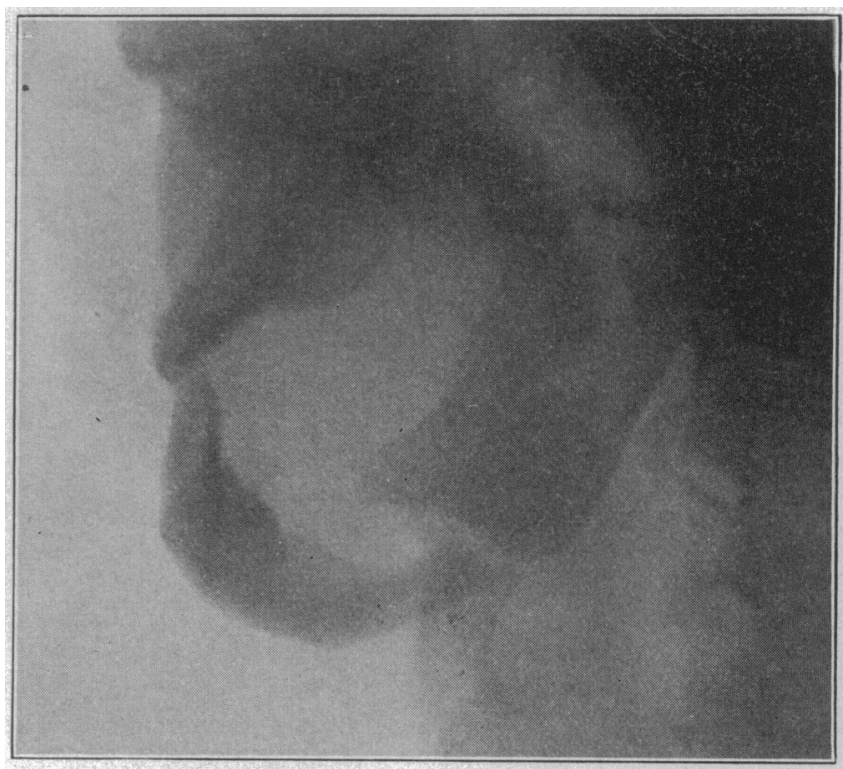

Fig. 6.-Double fracture which was badly infected; shows marked loss of bone because of exfoliation; poor result obtained.

after infection and necrosis, and perhaps aided by some constitutional disease such as syphilis, tuberculosis, etc.

We have had two cases of failure to unite in the foregoing series of 1,065 cases. This condition is also due to fibrous tissue and torn ends of periosteum coming between the edges of the bone and not allowing them to unite. Dr. Walter C. Cramp in 1911 reported

1. Cramp, Walter C.: Fracture of Tnferior Maxilla Complicated by
Complete Division of Facial Artery, Med. Rec., New York, Sept. 2, 1911. 
a case of rupture of the facial artery due to the fracture of the inferior maxilla. This is a very rare occurrence and I believe the only one on record.

Salivary fistula may sometimes result. as a sequence to fracture of the lower jaw, but this condition is extremely uncommon and does not occur unless the soft parts are greatly traumatized.

The diet of patients being treated for fractured jaws and wearing splints is one of a good deal of study and experimentation. It varies a great deal with the individual. My general method is to give the patient as many raw eggs (from four to six) per day and as much milk as possible (from 1 to 2 quarts) and feed every two hours. The diet ought to be carefully worked out for each patient, and the bowels, of course, must be kept open daily by means of efficient laxatives. Patients that have been wired by the Angle method for a month will often lose from 15 to 20 pounds. This, of course, is very weakening and one reason why the Angle wires and bands should not be used if other methods will suffice.

\section{CONCLUSIONS}

The inferior maxillary bone on account of its position and shape is the most frequently fractured bone of the face and about tenth on the list of all bones of the body to be fractured. About 98 per cent. of all fractures of the body of the bone are compounded when there are teeth present. And thus it is the most frequent bone to suffer a compound fracture. The fracture of this bone becomes infected on account of the fractures being compound, more than any other bone. The patient suffers great pain from injury to the inferior dental nerve and also from the inability to swallow, eat, drink and cough.

The fracture is about ten times as common in man as in woman. The most common age for the fracture of the bone is between 30 and 40 . The most frequent cause of the fracture is a blow of the naked fist. A line of fracture is most often at the region of the bicuspids on the left side. Fractures of the lower jaw depend a great deal on the occlusion of the upper and lower teeth. Fractures of the condyles are rare but are often followed by bony ankylosis. Fractures of the coronoid process are extremely rare and occur only when the zygomatic arch and the side of the face are severely crushed. Great care should be exercised in keeping the mouth clean in the treatment of fractures of the jaw. A cap splint or single arch splint should be used whenever there are one or more strong teeth on either side of the line of fracture to which the splint may be cemented. The interdental splint or intermaxillary splint should be used only in children, in edentulous mouths and in fractures posterior to the third molar when the upper and lower jaws cannot be wired together by means of Angle's wires and bands.

The open operation or surgical wiring of the fractured ends of the bone is unnecesary and generally results in infection and necrosis. The inferior maxillary bone can be more accurately reduced and held in better coaptation than other bones, as direct force can be applied to it by means of appliances attached to the teeth. Non-union very rarely occurs and is generally due to faulty or delayed treatment.

A roentgenogram should always be taken to ascertain the line of fracture, to discover the presence of impacted teeth and to note any infections or abscess conditions at the apicies of the teeth near the point of fracture.

\section{ABSTRACT OF DISCUSSION}

Dr. G. V. I. Brown, Milwaukee, Wis.: I wish Dr. Dunning would elaborate a little on a few matters which are sometimes disturbing to people who see fractures only once in a while. That is, the way he meets the conditions of the patient at the time of arrival at the hospital, or at least when called in an emergency. Dr. Dunning spoke casually of the treatment of these cases, but some, I think, require a little more treatment than he described. I find it necessary sometimes to make a temporary splint to give comfort, and I have made it quickly and rapidly out of a modeling compound. It is easily held in position by the use of the Barton bandage and will make the patient comfortable for a sufficient period of time, if necessary, to make it possible to do other work. When a man is thrown fiom an automobile he usually receives some other injury besides fractures and most of the time those are the things that give us most trouble. So that it is necessary sometimes to take care of cases through a critical period before we can adjust the fractures. I know that in his experience with 1,065 cases Dr. Dunning's observations would be valuable. I would ask him to speak about the manner of adjustment in these cases. I agree with him that, most of the time, a fracture of the condyle will adjust itself, if the rest of the jaw is held, with much less trouble than we can adjust it by wiring. There are conditions, however, due sometimes to the shape of the fracture and degree of the angle of the fracture, that should modify this statement. Because one case adjusts itself nicely without being held and without wiring, it would not necessarily follow that other cases, in almost the same situation perhaps, would do the same, because the angle of the fracture has to do with that. I think we agree that too much is done in fractures of the jaw. The less we do for them after using an appliance which will permit of constant surveillance, as far as possible, and give mobilization, the better. Unfortunately, too much is done in the way of cutting in and wiring the jaw. I do not believe in temporizing at all in the case of a jaw that requires wiring, but $I$ agree with Dr. Dunning that many are wired which should not be. Then again comes in as a part of this question, the manner of adjusting the wires, etc. We should understand the advantage of all methods which have been found most frequently successful.

Dr. M. I. Schamberg, New York: Dr. Dunning's statistics are intensely interesting, and I am sure that his experience in these cases, when we read them over carefully in his paper, should help us materially, particularly those of us who see far fewer cases. I have seen a large variety, but in no sense a large number. I have found, as has Dr. Dunning, the Roentgen ray intensely valuable, and in fact almost essential to absolute accuracy in most of these cases, for the reason that so frequently one will see fractures with spiculae of necrosed bone, or infection, or at times portions of the root, and in one instance both spiculae of bone and a piece of the root protruding into the fractured region, which would retard the healing. Another case to which I refer was a pathologic fracture of marked extent in which the Roentgen ray showed what looked like a compound comminuted fracture of a jaw that was ordinarily thick. I was inclined to suspect that this was produced primarily by arsenic necrosis, and this necrosed bone in the jaw was separated in many places. We dealt with this case in a manner that would not appear to you to be surgically correct, but by which the case culminated satisfactorily. All that appeared to be bone was nothing but a thin matrix and this acted as a matrix for new bone to form. The jaw was splinted on each side, and this patient wore the splint at an old age, resulting in the reduction of the fracture and the formation of a very useful jaw. The splint was removed after the patient wore it for six months and the result on that side is wonderful. I have a similar case in which there was extensive necrosis of the jaw and in which, after a similar appliance was worn, complete regeneration of the bone took place. I believe that much can be done by the application of what may be termed surgical prosthesis without real surgery, to bring about results that heretofore have not been achieved. 
Dr. Theodore Blum, New York: This appliance which Dr. Schamberg has spoken of is really not a splint in the ordinary sense of the word, but is the splinting of the jaws by means of a sliding joint. One point with regard to fractures is the splinting of the lower jaw to maintain its mobility, and the same principle is carried out in these pathologic fractures in a different way. At the University of Pennsylvania we were taught by $\mathrm{Dr}$. White that there were three points to be remembered in the treatment of fractures. First, reduce the fracture; secondly, maintain mobilization of the joint on either side of the fracture, and thirdly, maintain nutrition.

Dr. W. WAYNe BABCoCK, Philadelphia: Anyone who has gone to the trouble that Dr. Dunning has in collecting the data on such a large series of cases as this, nearly eleven hundred, every one of a single bone, is deserving of great credit, because it clarifies our knowledge with regard to certain points which have been in dispute, and confirms things which may have previously needed confirming. We are practically agreed as to the plan of treatment; as to the advantage of getting away from some of the older appliances, especially the interdental splint, and relying on operative intervention. Nature has already done about the worst she could do in the accident, and then it has been the tendency for the surgeon to step in and further traumatize the parts, and it is not surprising that necrosis and various ill results have followed. Then again, in these cases sometimes the question arises as to the external wound. In most cases we are safe in cleansing and closing any external wound on the face If the fracture is compound, let it be compound in the mouth and not from the face; and if one has been careful, as a rule, I believe the face would heal and drainage will take place in the mouth and to the same degree. Then as regards teeth that are somewhat loosened adjacent to the fracture, as a rule, I believe, Dr. Dunning feels that these may be left at the time to see what the results will be. Frequently teeth which look as though they must be sacrificed, if followed up, gradually become fixed; and of course, later on, spiculae of bone or any tooth that has become loosened may be removed at a time when the deformity may not be so great, or at a time when the removal may not bring about a greater deformity.

Dr. Henry S. Dunning, New York: I agree with Dr. Brown that a great many of these patients need attention other than that pertaining to the jaws. For instance, in one case, a woman was hit by a taxicab and among her injuries was the fracture of the jaw. This patient was unconscious when picked up and was suffering from a fractured rib and arm and concussion of the brain. This brings out a point in the paper that many fractures of the condyle are accompanied by fracture at the base of the skull, or fracture of the posterior wall of the glenoid cavity. I think Dr. Beck reports a case in which the patient died from abscess of the brain, due to a blow on the chin causing fracture of the base of the skull. I treat a great many of these cases in the hospital when the patient has received other injuries and has sometimes brain symptoms. I think the reason why the "knock-out blow" on the point of the chin is so famous is because the shock is so severe in a region that is close to the brain. The condyles are forced into the glenoid fossa, and being wedge-shaped, often cause a fracture into the cranium. With regard to surgical wiring, I have seen only one or two cases in over twelve hundred in which wiring had to be resorted to. Will Dr. Schamberg, who has had so much experience in the use of the Roentgen ray, say what angle is best from which to obtain a good roentgenogram of the condyle?. In one case nineteen roentgenograms were taken of the fracture, and the one shown was the best we could get and the patient was put in every conceivable position to get that. In most of the other roentgenograms we had the vertebrae overlapping the condyle.

How does Dr. Blum keep the two ends of the bone in apposition and allow the patient movement of the jaw at the same time, in fractures posterior to the third molar? I believe that it is poor treatment to wire the upper and lower jaws together when any other appliance can be used that will permit the patient to use the jaw while being treated.
I never do it unless the fracture is posterior to the third molar, or for some reason the teeth in the mouth cannot hold a splint to advantage. It is difficult often to keep the mouth clean when wired. Dr. Beck reports a case of inspiration pneumonia from a filthy mouth, wired for some weeks after a fracture, in which the mouth could not be kept clean, and in this case the patient died. I agree with Dr. Babcock that if we can possibly close the external wound, we should do so. Of course these wounds are mostly dirty or infected wounds and must often be drained. I think it is best to close these wounds partially, as soon as possible, but to leave one end open for a few days and allow it to drain and then later to fill in with granulations.

\section{A PORTABLE POSITIVE-PRESSURE APPA- RATUS FOR ADMINISTRATION OF ETHER BY INTRATRACHEAL INSUFFLATION}

\author{
ALLIE W. WILLIAMS, M.D. \\ Major Medical Corps, U. S. Army \\ WASHINGTON, D. C.
}

On account of the advances in head, neck and chest surgery, made possible by the use of the Meltzer-Auer method of administration of ether by intratracheal insufflation, I decided, at the suggestion of Dr. William M. Sweet of the Department of Experimental Surgery, University of Pennsylvania, to construct an apparatus suited to the needs of service conditions. In order to meet these conditions, it was necessary that the apparatus should "work" at all times, should be made easily transportable, and non-destructible by age from storage or climatic conditions. As a few parts of this apparatus had to be made of glass, as far as possible standard articles only were used.

Through the courtesy of Dr. Sweet, Dr. Charles H. Frazier and Dr. George Müller of the University of Pennsylvania, this apparatus was tested on both animals and patients at the University Hospital, and was exhibited in 1912, at the annual meeting of the American Medical Association, at Atlantic City, and the Military Surgeons' Association at Baltimore.

Recently I have had the opportunity of giving it a thorough test under field-service conditions in the surgical work at Field Hospital 3, Texas City, Texas, and since May 30, 1914, at Vera Cruz, Mexico. During this time the apparatus was essential to the successful performance of four surgical operations: (1) A plastic operation on the chest-wall for tuberculous necrosis of ribs, with tuberculosis of pleura and lungs; (2) dissection of bronchial fistula of neck; (3) resection of frontal bone for frontal sinusitis; (4) tuberculous abscess of neck. In the two latter operations the anesthetic was administered with this apparatus, using pharyngeal instead of intratracheal insufflation. The anesthetic was administered by Capt. H. C. Michie, Jr., Medical Corps, U. S. Army. That Captain Michie refers to it as "the lazy man's way of giving an anesthetic" is an evidence of the ease with which he was able to administer it with this apparatus.

At Philadelphia, while testing this machine, a curious incident happened at the University Hospital. A physician with some experience in the use of the Meltzer-Auer method of producing positive pressure in the lungs by intratracheal insufflation anesthesia, expressed some doubt as to the mechanism of distending the lungs against the chest-wall by means of intro- 